\title{
BIM-Based Cost Management Practices in the Quebec's Construction Industry
}

\author{
Ritha Oumbé $^{1}$ and Conrad Boton ${ }^{2}$
}

École de Technologie Supérieure, Montréal, Canada, ritha-edwige.oumbe-monteu.1@ens.etsmtl.ca

2 École de Technologie Supérieure, Montréal, Canada, Conrad.Boton@etsmtl.ca

\begin{abstract}
Construction projects are known for frequent cost overruns, due to different issues including the limitations of conventional cost management approaches. Building Information Modeling (BIM)supported cost management (5D BIM) consists in associating the cost variable with a BIM model in order to optimize the management of construction costs. Although several studies have been conducted in different countries to identify the benefits of, and barriers to, the implementation of 5D BIM, data on its implementation and associated practices in Quebec are missing. The objective of this study is therefore to present the general picture of the implementation of 5D BIM in the Quebec's construction industry. In order to achieve this objective, an in-depth literature review was conducted, and a questionnaire was developed and distributed to a sample of cost management specialists in the AEC industry in Quebec. The results suggest that that while 5D BIM is recognized to foster the production of better estimates, the automation of estimation is still far from being a reality. Excel is still the main tool for allocating costs to quantities extracted from BIM models and for estimates preparation. Thus, 5D BIM is mainly used for cost estimating, budgeting and cost control but much less for claims management.
\end{abstract}

(c) 2020 The Authors. Published by Budapest University of Technology and Economics \& Diamond Congress Ltd Peer-review under responsibility of the Scientific Committee of the Creative Construction Conference 2020.

Keywords: 5D BIM, construction cost management

\section{Introduction}

The Architecture, Engineering and Construction (AEC) industry is lagging in terms of technology adoption, compared to other industries. The traditional work in silos and the lack of collaboration greatly affect the productivity and the predictability of costs and schedules. Based on a study carried out on 258 infrastructure projects in 20 countries on 5 continents, Flyvbjerg et al. [1] concluded that almost nine out of ten projects are subject to a poor estimate of costs, with a probability of $86 \%$ for a given project being overestimated and $14 \%$ for being underestimated. According to the authors of the study, the real cost of construction is on average 28\% higher than the budgeted cost. Ma and Yan [2] explained that one of the problems of cost management is that companies find it difficult to adapt to new technologies. These can allow an optimization of the construction processes, leading to a considerable reduction of costs and times while improving quality. They can also be used for gathering information on the real market in order to make adequate planning for the acquisition of resources and for monitoring cost information on site in real time. They finally can allow integration of cost management from the start of the project by extracting quantities precisely in real time in the different phases, for real-time dynamic monitoring of costs on the site, for updating the estimate during implementation, for noting deviations and for taking the appropriate measures to correct them. Khanzode et al. [3] estimate an accuracy of 3\% between the budgeted cost and the cost at completion by integrating Building Information Modeling (BIM) approach at the start of the project. 
However, the AEC industry in Quebec seems still reluctant, although this approach and its various tools to support cost management (5D BIM) have been around for a while and have been widely implemented around the world. In fact, only $31 \%$ of industry professionals claim to have adopted BIM [4]. No study has been specifically carried out on the implementation of 5D BIM in Quebec. The practices and issues specific to the use of 5D BIM in the Quebec construction industry are therefore not known. The main objective of the study reported in this paper is to present the general picture of the practices associated with the implementation of 5D BIM in the construction industry in Quebec. Specifically, the study aims at determining what are the current 5D-based cost management practices and the software used industry; and at identifying the perceived benefits, from the perspective of 5D BIM specialists in Québec.

\section{5D BIM adoption around the world}

5D BIM consists in associating the cost variable with a BIM model, either by incorporating the cost data into the objects of the BIM model themselves, or by making a direct living link between a BIM model and an estimation software [5] [6]. Parametric modeling therefore facilitates the creation of a relationship between elements and includes the specification and properties of individual elements and objects, allowing the extraction of complete and precise information from the model which can be directly used for costing [7]. Indeed, the quantities can be extracted directly and instantly from the BIM model with a high level of precision. By assigning the unit cost to the quantities extracted, it is possible to automatically obtain an accurate and reliable cost analysis. As a result, modifications can be efficiently made in real time and an assessment of the impact of the change on the cost of the project.

According to Smith [8], the most comprehensive survey of quantity surveyors' use of BIM in the world was that of Royal Institution of Chartered Surveyors (RICS) [9] in the United Kingdom and the United States. The survey provides an overview of the level of adoption of BIM by quantity surveyors and the problems encountered which could well apply to many other countries in which quantity surveyors practice. Out of 298 participants, only $10 \%$ of quantity surveyor companies used BIM regularly, and $29 \%$ had limited engagement with BIM. As a result, $61 \%$ of companies had no engagement with BIM. For quantity surveyors using BIM, the most common use was construction planning (14\%), followed by quantity extraction and facilities / asset management ( $8 \%$ each). Only $4 \%$ of companies regularly invest in BIM training and only $10 \%$ actively assess BIM tools with a view to their potential adoption [9]. This indicates that the profession of quantity surveyor in this region is not adopting BIM to the required level. However, since the British government's mandate regarding the use of BIM was introduced at the time of this survey, it would be interesting to see what effect this has had on the companies of quantity surveyors since then [8]. In the UK, a 2016 Software Advice survey of Small and Medium-Sized Companies found that $60 \%$ of users were looking for cost estimation software options and $24 \%$ of respondents wanted to increase transparency and the level of monitoring projects. However, $50 \%$ still use manual methods to calculate costs, prepare contracts and project management [10].

According to Boon and Prigg [5], 5D BIM is relatively little used in New Zealand due to a number of obstacles limiting its implementation in the industry. A survey of 20 quantity surveyors in New Zealand found that almost all of the respondents had participated in fewer than five projects using 5D BIM [5]. By comparing the implementation of BIM in Iceland and in the Scandinavian countries it emerges that the BIM utilization rate for cost estimate is $14 \%$ higher in the average of the Scandinavian countries. The data on tendering and extracting quantities is also interesting. In this case too, the Scandinavian countries are in the foreground with $9 \%$ and $18 \%$ respectively [10].

In Slovakia, $12.9 \%$ of companies use 5D BIM tools, but only for bill of quantities, and only $6.5 \%$ use it for bill of quantities and the budget itself. Interesting conclusions on the state of BIM implementation in Slovakia were presented by research by Mesároš, Selín and Mandičák [10], which aim was to identify cost management approaches in Slovak construction companies. The research has shown the influence of using BIM to reduce costs in small companies. This finding is mainly because BIM technology is mainly used by the designers who represented small companies in this research [10]. 
As we can see, 5D BIM is widely implemented around the world. However, data on its implementation in the AEC industry in Canada and more specifically in Quebec are lacking. The objective of this study is therefore to create an overview of the implementation of 5D BIM in the Quebec's AEC industry and to determine the professionals' perception of its benefits.

\section{Research approach}

A questionnaire survey approach was adopted because it allows reaching a large sample of a population. The target population of the study was professionals in the AEC industry in Quebec with a good knowledge of BIM in general and BIM-based cost management in particular. Our sample was a

convenience sample, of a non-probabilistic type, made up of subjects who freely and voluntarily consented to participate in the research in its entirety. All responses were kept confidential, and participants' anonymity was ensured. Ethics approval was sought and obtained from the ethics and research committee of authors' institution.

An in-depth literature review of previous studies on the implementation of 5D BIM, its Benefits and challenges was first conducted. We then formulated some questions and carried out an interview with the director and one manager of the preconstruction department of one of the largest construction companies in Quebec. This interview allowed us to better orient the questionnaire. Once elaborated, we submitted our questionnaire to an intermediate estimator working in another large construction company and having a good knowledge of BIM to test it before we distributed it. Invitations to respond to the questionnaire were sent by email to participants. 42 invitations were sent, and 17 participations were received.

The participants in the study are mainly in the estimation field (65\%) which is completely normal given that our target audience were construction professionals with knowledge of BIM-based cost management. Then we have planners (53\%), consultants (29\%), designers (24\%), and finally the others (29\%) working in support and management.

Most participants (41\%) work for large companies (more than 100 employees). 29\% work for mediumsized companies (51 to 100 employees), 18\% for small companies (6 to 50 employees) and 12\% for micro companies ( 1 to 5 employees). This can be explained by the fact that large companies have more resources and are more open to the implementation of new technologies such as BIM.

\section{Findings}

\subsection{Uses of BIM for cost management}

Of the 14 companies that responded using BIM, five (5) responded that they did not use it for cost management (5D BIM), or $35.71 \%$. An in-depth analysis revealed that out of these five companies, three (3) are large companies and two (2) are medium-sized companies. These figures tend to mean that large and medium-sized businesses seem more resistant to the use of 5D BIM, which is quite contradictory because they have the resources necessary for its implementation, which indicates that issues other than configuration costs are involved. 


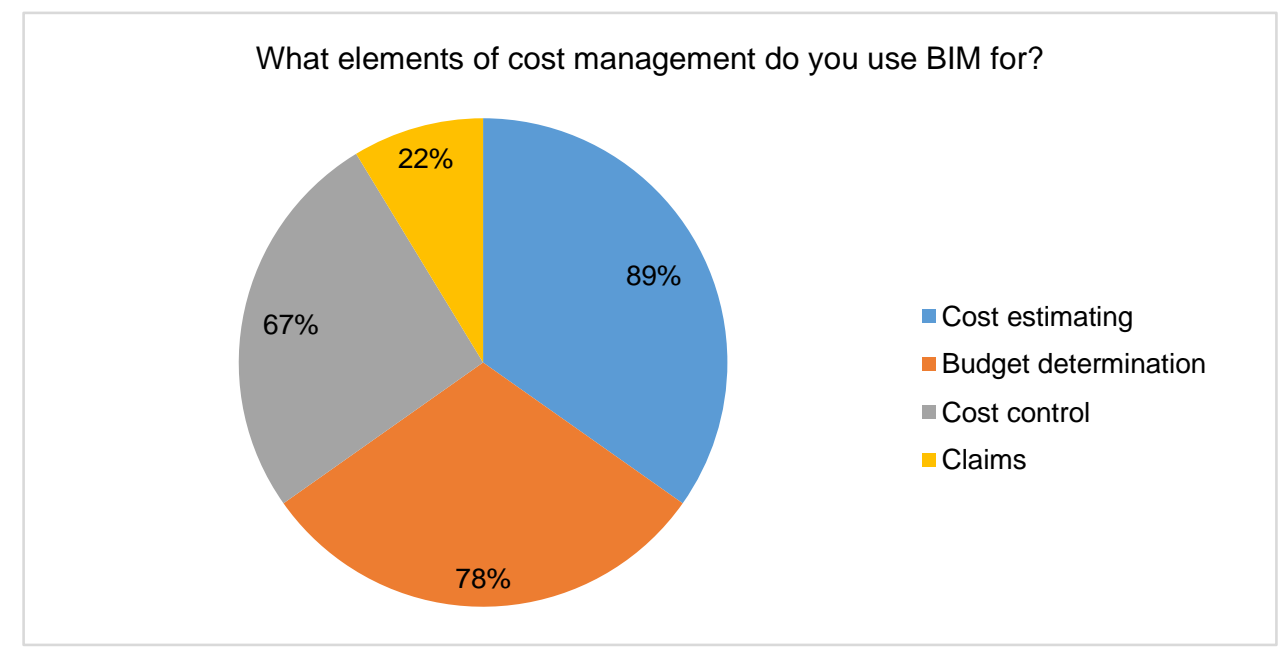

Fig. 1. Elements of cost management for which BIM is used

BIM is mainly used for cost estimating (88.89\%), for budget determination (77.78\%), for cost control (66.67\%) and for claims management $(22,22 \%)$ as illustrated in Fig. 1.

\subsection{The software used}

For each element of cost management, participants had to specify which 5D BIM tools they use. The results are summarized in Fig. 2.

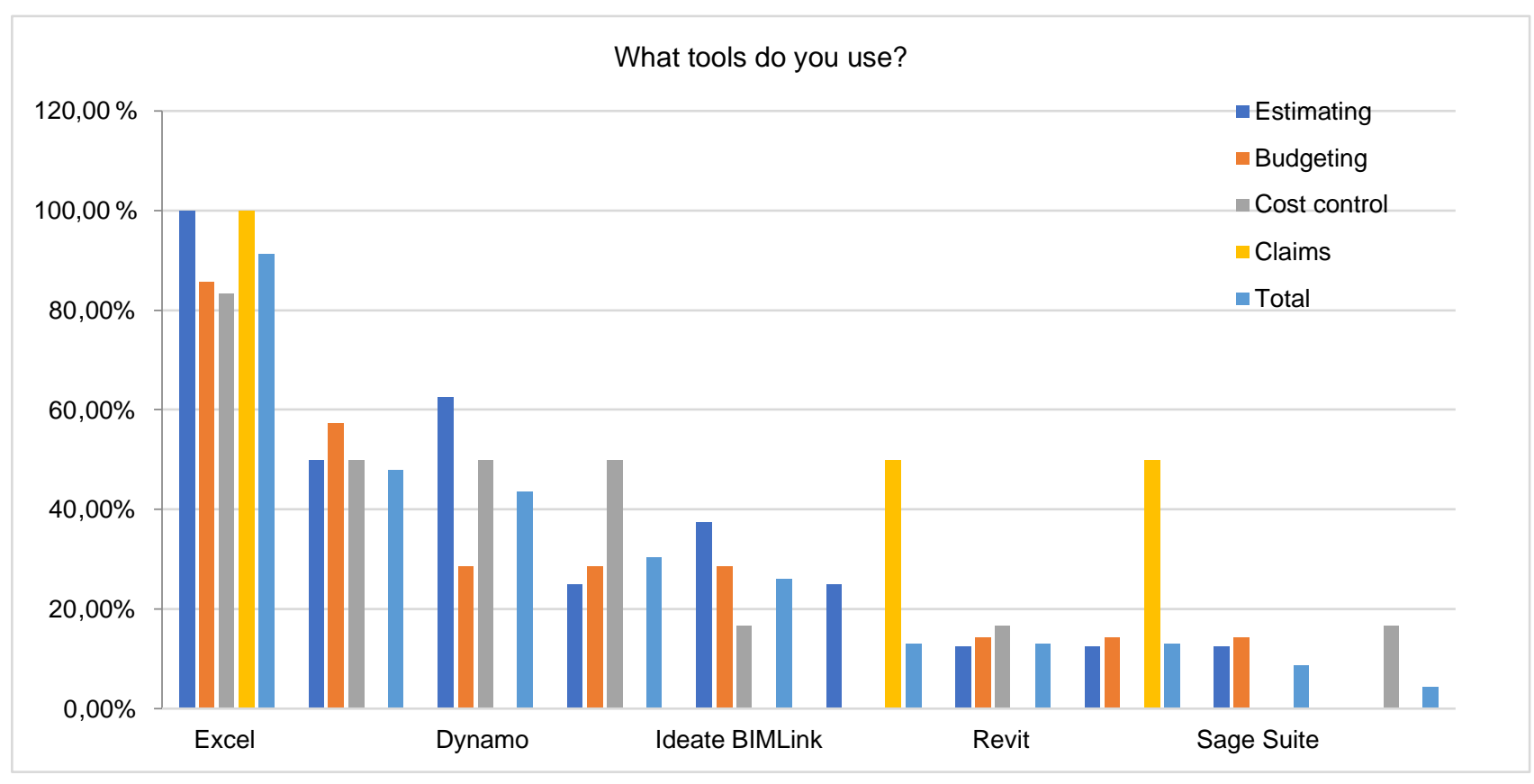

Fig 2. 5D BIM tools used

The three most used tools are Excel, CostX and Dynamo. Although Excel is not strictly speaking a 5D BIM estimation software, it remains the most used tool by participants regardless of the cost element. Next is CostX which is the second most used tool for budgeting, third for estimation and second with Dynamo and Navisworks for control. Dynamo is the third most used tool, it is second for estimation, third tied for budgeting and second for control.

\subsection{Perceived benefits of $5 D$ BIM}

An analysis allowed us to assign marks out of 5 to each advantage and thus to rank in order to highlight the Benefits most perceived by professionals. The results are reported in Table 1. 
Everyone agrees that BIM 5D produces better estimates thanks to the ability to model project options before and during construction. By considering project options early, fewer variations are likely to occur during construction [11]. Olatunji et al [12] suggest that BIM allows professional quantity surveyors to identify factors that have economic benefit or consequence on various design options in order to select the most suitable and cost-efficient proposal. Furthermore, early design advice "should lead to increased client satisfaction as they are receiving earlier economic feedback on the alternatives available" [13].

Table 1. Perceived benefits of 5D BIM

\begin{tabular}{|c|c|c|c|c|c|c|c|}
\hline & [NB: 1 = totally disagree, $5=$ totally agree] & 1 & 2 & 3 & 4 & 5 & Score $/ 5$ \\
\hline B.1 & $\begin{array}{l}\text { The estimation is improved thanks to the possibility of modeling the } \\
\text { project optio|ns before and during construction. }\end{array}$ & & & & 1 & 6 & 4,9 \\
\hline B.2 & $\begin{array}{l}\text { Project visualization is increased, which reduces errors in drawing } \\
\text { interpretation and improves decision-making. }\end{array}$ & & 1 & & & 7 & 4,6 \\
\hline B.3 & $\begin{array}{l}\text { Collaboration, communication and information sharing between project } \\
\text { teams is improved. }\end{array}$ & & & 1 & 2 & 5 & 4,5 \\
\hline B.4 & 5D BIM provides a business advantage over competitors. & & & & 4 & 4 & 4,5 \\
\hline B.5 & $\begin{array}{l}\text { Risk identification is done earlier: the detection of potential conflicts is } \\
\text { improved, at an earlier stage than with traditional approaches. }\end{array}$ & & & 1 & 3 & 4 & 4,4 \\
\hline B.6 & $\begin{array}{l}\text { Design changes can be identified more easily and quickly by overlapping } \\
\text { previous BIM models with revised BIM models. }\end{array}$ & & & 1 & 3 & 4 & 4,4 \\
\hline B.7 & The ability to resolve requests for information in real time & & & 1 & 3 & 4 & 4,4 \\
\hline B.8 & $\begin{array}{l}\text { Conceptualization of the project is made easier: 3D makes it easier to } \\
\text { determine the cost of design options at the start of the design phase. }\end{array}$ & & & 2 & 2 & 4 & 4,3 \\
\hline B.9 & $\begin{array}{l}\text { 5D BIM allows more efficient preliminary estimates (by automatic } \\
\text { generation of quantities from objects in the BIM model). }\end{array}$ & 1 & 1 & & 1 & 5 & 4,0 \\
\hline B.10 & $\begin{array}{l}\text { 5D BIM allows more efficient detailed estimates (by automatic generation } \\
\text { of quantities from objects in the BIM model). }\end{array}$ & & 1 & 1 & 3 & 3 & 4,0 \\
\hline B.11 & $\begin{array}{l}\text { The details of the provided preliminary bills of quantities more accurately } \\
\text { reflect the scope of the work involved. }\end{array}$ & & & 3 & 2 & 3 & 4,0 \\
\hline B.12 & $\begin{array}{l}\text { Automatic generation of quantities allows more time to be spent on other } \\
\text { cost management services for the client (e.g. cost advice on more design } \\
\text { options) }\end{array}$ & & 1 & 2 & & 4 & 4,0 \\
\hline B.13 & $\begin{array}{l}\text { 5D BIM enables more efficient production of bills of quantities (by } \\
\text { automatic generation of quantities from objects in the BIM model). }\end{array}$ & 1 & & 1 & 2 & 3 & 3,9 \\
\hline
\end{tabular}

\section{Conclusion}

This research presented the general picture of the implementation of 5D BIM in the AEC industry in Quebec. More specifically, current 5D cost management practices and tools are identified and the benefits of 5D BIM implementation are explored.

The survey shows that 5D BIM is mainly used for cost estimating, then for budgeting and cost control, and to a lesser extent for claims management. These results suggest that the automation of cost management is still far from being a reality. Even if quantities are automatically extracted from BIM models, Excel is still the main tool for manually allocating costs to them and for preparing estimates. The main perceived benefits of 5D BIM turned out to be improved estimates thanks to the possibility of modeling project options before and during construction, better visualization of the building, improved collaboration between project teams and the granting of a commercial advantage over competitors.

Even if the study provides an overview of practices in the industry, it is important to note that the small size of our sample may not allow us to extrapolate the results to the scale of the AEC industry in its entirety. 
Indeed, the main difficulty of the project was to obtain participation in the survey, professionals being reluctant to answer it although anonymity was guaranteed. Nevertheless, the results obtained give a good overview of how professionals perceive 5D BIM, what uses they make of it and its advantages.

\section{References}

[1] B. Flyvbjerg, M. K. Skamris holm and S. L. Buhl, "How common and how large are cost overruns in transport infrastructure projects?," Transport Reviews, 23:1, pp. 71-88, 2003. https://doi.org/10.1080/01441640309904

[2] Z. Xia Ma and G. Cai Yan, "Analysis on the Problems and Measures to the Construction Project Cost Management.," Advanced Materials Research (Volumes 971-973), p. 2458-2461, 2014. https://doi.org/10.4028/www.scientific.net/AMR.971-973.2458

[3] Khanzode, M. Fischer and D. Reed, "Benefits and lessons learned of implementing building virtual design and construction (VDC) technologies for coordination of mechanical, electrical, and plumbing (MEP) systems on a large healthcare project," ITcon Vol. 13, 2008.

[4] S. Tahrani, D. Forgues and E. Poirier, "L’adoption du BIM et des approches intégrées au Québec," 2015.

[5] J. Boon and C. Prigg, "Evolution of Quantity Surveying Practice in the Use of BIM - the New Zealand Experience," Proceedings, Joint CIB International Symposium of W055, W065, W089,W118, TG76, TG78, TG81 \& TG84, pp. 84-98, 2012.

[6] M.-A. Vigneault, C. Boton, H.-Y. Chong and B. Cooper-Cooke, "An innovative framework of 5D BIM solutions for construction cost management: A systematic review," Archives of Computational Methods in Engineering, 2019. https://doi.org/10.1007/s11831-019-09341-z

[7] C. Eastman, P. Teicholz, R. Sacks and K. Liston, BIM Handbook: A Guide to Building Information Modeling for Owners, Managers Designers, Engineers, and Contractors, Hoboken, New Jersey: John Wiley \& Sons, 2011.

[8] P. Smith, "BIM \& the 5D Project Cost Manager," Procedia - Social and Behavioral Sciences, vol. 119, p. 475 - 484, 2014. https://doi.org/10.1016/j.sbspro.2014.03.053

[9] RCIS, "RICS 2011 Building Information Modelling Survey Report," 2011.

[10] P. Mesároš, J. Smetanková and T. Mandičák, "The Fifth Dimension of BIM - Implementation Survey," in IOP Conference Series: Earth and Environmental Science, 2019. https://doi.org/10.1088/1755-1315/222/1/012003

[11] R. Stanley and D. Thurnell, "The Benefits of, and Barriers to, Implementation of 5D BIM for Quantity Surveying in New Zealand," Australasian Journal of Construction Economics and Building, vol. 14, no. 1, pp. 105-117, 2014. https://doi.org/10.5130/ajceb.v14i1.3786

[12] O. Olatunji, W. Sher and N. Gu, "Building information modeling and quantity surveying practice," Emirates Journal for Engineering Research,, vol. 15, no. 1, pp. 67-70, 2010.

[13] N. Thurairajah and D. Goucher, "Advantages and Challenges of Using BIM: a Cost Consultant's Perspective," in 49th ASC Annual International Conference Proceedings, San Luis Obispo, USA, 2013. 